\title{
Secondary care usage and characteristics of hospital inpatients referred to a UK homeless health team: a retrospective service evaluation
}

Hannah Field $d^{1,2^{*}}$, Briony Hudson ${ }^{2,3}$, Nigel Hewett ${ }^{2}$ and Zana Khan ${ }^{2,4}$

\begin{abstract}
Background: UK "Pathway" teams offer specialist hospital care coordination for people experiencing homelessness. Emergency healthcare use is high among homeless people, yet "homelessness" is not routinely coded in National Health Service (NHS) data. Pathway team records provide an opportunity to assess patterns in admissions and outcomes for inpatients identified as homeless.

Methods: Retrospective analysis of patients referred to "Pathway" homelessness teams in seven UK hospitals to explore the patterns of hospital admission, morbidity, secondary healthcare utilisation and housing status. Each patient was individually identified as experiencing homelessness. Within a six-month period, demographic data, reason for admission, morbidity, mortality and secondary care hospital usage 120-days before and 120-days after the index admission was collected.

Results: A total of 1009 patients were referred, resulting in 1135 admissions. Most admissions had an acute physical health need (94.9\%). Co-morbid mental illness and/or substance misuse was common (55.7\%). Reasons for admission included mental and behavioral disorders (overdose, alcohol withdrawal or depression, 28.3\%), external causes of morbidity and mortality (assault or trauma, 18.7\%), and injury, poisoning and external causes (head injury, falls and fractures, 12.4\%). Unplanned Emergency Department attendances reduced after index admission and unplanned hospital admissions increased slightly. Planned admissions doubled and total bed days increased. Housing status was maintained or improved for over $60 \%$ of inpatients upon discharge. Within 12 months of index admission, 50 patients (5\%) died, 15 deaths (30\%) occurred during the index admission.

Conclusions: Disengagement with health services is common among homeless people. Many deaths are due to treatable medical conditions (heart disease, pneumonia, cancer). Observed increases in planned admissions suggests intervention from Pathway teams facilitates necessary investigations and treatment for homeless people. Equity, parity of care, and value should be inbuilt interventions for inclusion health groups and evaluations need to move beyond simply seeking cost reductions.
\end{abstract}

Keywords: Homeless person, Patient readmission, Health services research, Cost savings, Inclusion health, Pathway, Hospital medicine, Retrospective study

\footnotetext{
*Correspondence: hannah.field@nhs.net

${ }^{1}$ Royal Surrey County Hospital, Egerton Road, Guildford GU2 7XX, UK

${ }^{2}$ Pathway, 250 Euston Road, London NW1 2PG, UK

Full list of author information is available at the end of the article
}

(c) The Author(s). 2019 Open Access This article is distributed under the terms of the Creative Commons Attribution 4.0 International License (http://creativecommons.org/licenses/by/4.0/), which permits unrestricted use, distribution, and reproduction in any medium, provided you give appropriate credit to the original author(s) and the source, provide a link to the Creative Commons license, and indicate if changes were made. The Creative Commons Public Domain Dedication waiver (http://creativecommons.org/publicdomain/zero/1.0/) applies to the data made available in this article, unless otherwise stated. 


\section{Background}

\section{What is already known on this topic}

Recent international evidence reviews define Inclusion Health Groups (IHGs) as overlapping populations including those experiencing homelessness, prisoners, people who sell sex and people with substance use disorders [1, 2]. IHGs experience extreme health inequity, high morbidity and premature mortality [2]. Due to barriers such as stigma and difficulty making and keeping appointments, use of primary care services are low for IHG's, while emergency healthcare use is high, often due to a healthcare crisis [3]. Duration of admission has been estimated to be three times longer for homeless patients who often experience poor hospital discharge arrangements [3]. This is likely to reflect ongoing and unaddressed care and housing needs [4]. All IHGs have frequent contacts with services, including emergency hospital attendances, but under-utilise scheduled and primary care due to a combination of chaotic lifestyles and barriers to registering and attending appointment based services [5-7]. This pattern of care focuses on addressing one problem, but fails to address a person's broader health and care needs. This results in missed opportunities, poor health outcomes and significant costs to health and public services $[8,9]$.

Inclusion health $(\mathrm{IH})$ describes an emerging movement which aims to prevent and redress the harms of extreme inequity among the most excluded populations through advocacy, policy, research, education, practice and service provision [1]. This agenda has encouraged the development of specialist primary and secondary healthcare and improving mainstream health and care provision for IHGs including people experiencing homelessness [1, 10-12].

\section{What this study adds}

This study provides the first analysis of admissions for people referred to hospital-based homelessness teams across the UK. In this sample, patients experiencing homelessness were most commonly admitted for ICD10 categories consistent with the life experiences of people living with poverty, deprivation and social exclusion, such as mental and behavioural disorders and external causes of morbidity and mortality. This study provides evidence for rethinking the definition of success for interventions aimed at improving the health of people experiencing homelessness. We suggest moving beyond seeking cost reductions to considerations of equity, parity of care and value $[13,14]$.

\section{Introduction}

Homelessness takes many forms, living and sleeping on the street (rough-sleeping) remains the most visible form of homelessness, but as many as 170,000 people in
Britain reside in other insecure settings [15] including homeless hostels, "sofa-surfing" (living temporarily with others), living in squats or other unsuitable and temporary accommodation such as bed and breakfasts [16]. The annual Government count of rough-sleepers estimates 4677 people slept rough on one night in Autumn 2018 [17] an increase of $165 \%$ since 2010 [18]. Research evidence suggests that the figure is actually around 24,000 including people sleeping in tents and cars [19]. These rapid increases in homelessness are underpinned by poverty and adverse life experiences but driven by austerity, welfare cuts, lack of affordable housing, and sustained cuts in the local authority services that support these groups $[8,20]$.

Homelessness is characterised by complex health and care needs often including "tri-morbidity" - the combination of physical illness, mental illness, and substance use disorders [3, 21-23]. A recent systematic review showed standardised mortality rates (SMRs) across IHGs are ten times that of the general population [2]. Although SMRs are highest for deaths from causes including overdoses, suicide, accidents and violence, they were also more than doubled for treatable conditions such as coronary heart disease, pneumonia and cancers, which account for the majority of deaths [2]. More secondary care for treatable conditions is a beneficial outcome for the individuals and for health equity, even if this results in increased costs.

The reported mean age of death for people experiencing homelessness is 42 for women and 44 for men [24, 25]. Barriers to accessing scheduled and primary care include perceived stigma and discrimination, difficulty making and keeping appointments [26], difficulty registering with a GP due to lack of identification and address [2], competing priorities [27], communication difficulties or challenging behaviour [8, 9, 28, 29]. In 2010, when homelessness was less prevalent, the estimated cost of unscheduled and emergency care was $£ 85$ million, but recent evidence shows that Emergency Department attendances (in the UK referred to as Accident and Emergency or A\&E) of people experiencing homelessness have increased three fold since 2010/11 [30]. Therefore, secondary care has been one focus of interventions to improve care of people experiencing homelessness and other IHGs.

One model developed by the UK's leading homeless healthcare charity, Pathway, includes specialist in-reach hospital care coordination teams, led by a specialist General Practitioner (GP), known as Pathway teams. These teams provide advocacy, advice and support both for the patient and for the admitting clinical team and liaise with community health and housing providers. Specialist GPs undertake hospital ward-rounds of homeless inpatients and are supported by senior clinical staff including 
nurses, social workers or occupational therapists (OTs), housing officers and Care Navigators (employees who have lived experience of homelessness and are best placed to support homeless inpatients) [10, 31, 32]. Several small observational studies have suggested a subsequent reduction in secondary care usage [10, 33, 34]. A two-centre randomised controlled trial did not confirm this finding but did show improved health and housing outcomes resulting in a cost effective intervention [35]. Pathway have trained ten hospital-based teams across the country, which operate as part of NHS services, this specialist care coordination for patients experiencing homelessness is hereafter called the "Pathway Intervention".

While morbidity and mortality rates of people experiencing homelessness in primary care settings have been explored [36, 37], little research exists around the diagnostic reasons for hospital admissions for this group. Homelessness is not routinely coded in NHS data, making the identification of people experiencing homelessness within NHS records problematic. However, all the patients supported by Pathway teams are confirmed as homeless. We undertook a retrospective analysis of the records of Pathway homelessness teams across the UK to investigate morbidity patterns in this group and to look for any changes in secondary care usage after the Pathway intervention. We investigated:

- the recorded reasons for admission to hospital for patients seen by Pathway homelessness teams within a six-month period (1st January to 30th June 2016).

- secondary healthcare usage in the 120-days prior to and following this index admission and discharge.

- any change in housing status in the 120-days following index admission in comparison to housing status upon admission.

\section{Methods}

\section{Study design and setting}

A retrospective analysis of all admissions to secondary care involving Pathway teams located in hospitals in seven locations across the UK, over a six-month period (1st January to 30th June 2016). The medical records of identified patients were examined, and data extracted relating to secondary healthcare usage and housing status 120-days before their index admission and 120-days after discharge. Following an extensive search of the literature, there was no agreed methodology for this type of dataset and time-periods ranged from 30-days to 120 days before and after a defined intervention. The 120day timeframe was selected to allow assessment of sustained discharge from hospital and capture a thorough picture of secondary care usage. Where available, the reasons for the index admission were gathered. Nonadmitted patients (such as those seen in A\&E or the community) and referrals not assessed by a Pathway team were excluded. The index admission and A\&E attendance were not included in either the "before" or "after" analysis of secondary care usage to avoid weighting either data set.

Of the ten Pathway teams, seven were assessed covering: Bradford, Brighton, Manchester and four London based teams. The composition and size of Pathway teams vary according to the local scale of the challenge and available funding, but they all include GP leadership and a multidisciplinary approach. Excluded Pathway teams were Bristol (which was not in operation during the study period), Leeds (unable to visit due to team re-structuring) and the South London and Maudsley (which focuses on mental health).

\section{Study population}

We assumed that all patients who had been referred and assessed by the Pathway teams were experiencing homelessness of some kind, as this was a requirement for engagement with these services. Individuals were identified by a unique identifier (medical record number). Data from patients referred, assessed and admitted to acute hospital trusts by Pathway teams between January and July 2016 were included.

\section{Data extraction}

Patient data (clinical, demographic and admission related data relating to index admission) was retrospectively extracted from hospital records, hospital discharge summaries and Pathway databases within each study site and entered anonymously into an excel template by the researcher (HF). Data relating to admissions and A\&E attendances 120-days prior to admission and 120-days following discharge was also extracted and the reason for attendance recorded. Housing status on admission and discharge was recorded, where available. Table 1 outlines all variables collected, and the sources from which this data was obtained. Each patient was assigned a unique code to maintain anonymity and no identifiable patient information was included. For data extraction template, see Additional file 1.

\section{Data analysis}

The first admission for each patient occurring between 1st January 2016 and 30th June 2016 was identified as their "index admission." This may or may not have been the first time that the patient had contact with the Pathway team. Each index admission was analysed independently, regardless of whether a patient re-attended in this timeframe. Frequent attenders were included to provide an accurate representation of patients presenting to the service. Length of stay was calculated by taking the date of admission from the date of discharge. For inpatients 
Table 1 Data extracted from Pathway database, hospital records and hospital discharge summaries

\begin{tabular}{|c|c|}
\hline Outcome & Data source \\
\hline \multicolumn{2}{|l|}{ Demographic characteristics } \\
\hline Age during admission & Pathway database and hospital record \\
\hline Gender & Pathway database and hospital record \\
\hline Nationality/ recourse to public funds & Pathway database \\
\hline Housing status & Pathway database \\
\hline \multicolumn{2}{|l|}{ Clinical characteristics } \\
\hline Primary reason for admission (ICD-10 code) & Hospital discharge summary \\
\hline Secondary reason for admission (if applicable) & Hospital discharge summary \\
\hline Multi-morbidity & Pathway database \\
\hline Deaths (where applicable) & Hospital record \\
\hline \multicolumn{2}{|l|}{ Admission characteristics } \\
\hline Length of admission (days) & Hospital discharge summary \\
\hline Type of admission (planned or unplanned) & Hospital discharge summary \\
\hline Whether a surgery or procedure took place & Hospital discharge summary \\
\hline $\begin{array}{l}\text { Whether the admission was related to a recent trauma (road traffic } \\
\text { accident, assault, overdose, other) }\end{array}$ & Hospital discharge summary and Pathway database \\
\hline Whether drugs and/or alcohol were involved in circumstances of admission & Hospital discharge summary and Pathway database \\
\hline Type of discharge (self-discharge or medical discharge) & Hospital discharge summary and Pathway database \\
\hline \multicolumn{2}{|l|}{ Secondary care usage } \\
\hline $\begin{array}{l}\text { Readmission and A\&E attendances 120-days prior to admission and } \\
\text { 120-days following discharge }\end{array}$ & Hospital record \\
\hline $\begin{array}{l}\text { Characteristics of A\&E attendances and admissions (length of admission, } \\
\text { type of admission, reason for admission) }\end{array}$ & Hospital discharge summary \\
\hline
\end{tabular}

who died during the admission, date of death was used to calculate length of stay.

The International Classification of Diseases, tenth revision (ICD-10) [38] was used to categorise diagnostic reasons for admission provided. Each admission was allocated a primary diagnosis and, where present, a secondary diagnosis in order to capture the complexity of health need and prevalence of co-morbidities. ICD-10 diagnostic categories were summarised leading to a descriptive analysis of reasons for admission. Two researchers $(\mathrm{HF}$ and $\mathrm{BH})$ categorised half of the data each using the ICD-10 online table and consensus was agreed amongst authors for coding any ambiguous diagnoses. The main reason for attending hospital was allocated as the primary diagnosis and another consequence of this was allocated the secondary diagnosis. The researchers then re-checked the coding of the entire data set and measures of agreement were calculated $(\mathrm{k}=.815$, 95\% CI, $0.01-1.62, p<.001$ for the first $10 \%$ of the data) to ensure uniformity in categorisation.

Descriptive statistics were used to describe reasons for referral and secondary health care usage in the 120-days following discharge for each patient. Number of hospital attendances 120-days prior to the index admission were compared to those 120-days following discharge from the index admission using paired t-tests assuming continuous variables from independent observations with minimal outliers. Three types of hospital attendance were recorded: A\&E attendance (presentation to the emergency department not requiring hospital admission), unplanned admission (unscheduled admission to hospital) and planned admission (scheduled admission for a procedure or treatment, organised in advance).

Change in housing status from admission to discharge was coded as either an improvement, deterioration or no change. An example of deterioration in housing status would be if a patient moved from private rented or hostel, to sofa-surfing, or from sofa-surfing or hostel, to rough-sleeping. An improvement would be assigned if the reverse were true.

\section{Missing data and handling}

Missing data was encountered throughout data collection. Where percentages were calculated, the percentage of data missing was taken into consideration as a separate category for clarity, consequently other percentages may be an under-representation. Patients were not excluded if there was missing data for any of the variables collected. Repeat admissions and referrals to a Pathway team during the study period were included as 
a separate index admission in order to reflect the manner in which these patients use services, (this accounted for less than $10 \%$ of the patients referred).

\section{Ethics}

As a service evaluation this study was exempt from ethical approval requirements [39]. An honorary contract was obtained for HF from each hospital trust for data collection. All data was fully anonymised prior to analysis.

\section{Results}

Number of referrals and admissions

Throughout January to July 2016, 1663 patients experiencing homelessness were referred across the seven Pathway teams. Almost one third of referrals were not admitted to hospital and were therefore excluded $(n=$ $528,31.7 \%)$. Almost $70 \%$ of referrals $(n=1135,68.3 \%)$ resulted in hospital admissions and were included. These referrals comprised of 1009 (88.9\%) individual patients. Ninety-one (9\%) with 217 attendances to hospital were re-referred and re-assessed by a Pathway homeless team within the six-month period.

\section{Demographic characteristics}

The average age at admission across the seven teams was 43 years (SD 22.8) (Table 2). Average age was consistent across the teams. Over three quarters $(77 \%, n=$ 877 ) of patients were male. Male to female ratios were also consistent across teams. Seventy-five people (6.6\%) were found to have "no recourse to public funds" (NRPF) which results in limited access to certain statutory services such as welfare benefits or housing from a local authority.

Regarding housing status, the largest group of patients ( $n=473,41.7 \%)$ were categorised as having no fixed abode or rough-sleeping. Almost a quarter of patients $(n=259)$ reported living in a hostel or temporary accommodation and just over 10\% $(n=126)$ were living in council housing or a facility delivering medical care. One-hundred records had missing data for housing status $(8.8 \%)$.

\section{Clinical characteristics ICD-10 diagnoses}

There was a broad spectrum of reasons patients experiencing homelessness were admitted to secondary care (Table 3). As well as alcohol related admissions such as pancreatitis, gastritis, decompensated alcoholic liver disease and cirrhosis, many patients were admitted for physical health problems unrelated to alcohol, such as deep vein thrombosis, myocardial infarction, pneumonia, sepsis and status epilepticus. Admissions were largely appropriate for acute hospital treatment. For full categorisation of diagnoses with ICD-10 codes, see Additional file 2.

The most common ICD-10 category for both primary and secondary diagnosis was (V) Mental and Behavioral Disorders (28.3\%) including overdose (6.9\%), alcohol intoxication or withdrawal (8.0\%), and suicidal ideation (1.9\%) (Fig. 1). When taking into account primary and secondary diagnoses, (XX) External causes of morbidity and mortality made up $18.7 \%$ of admissions (including road traffic accidents (1.9\%), assault (2.3\%) and stabbing $(1.5 \%))$, (XIX) Injury, poisoning and certain other

Table 2 Demographics and clinical characteristics of analysed admissions

\begin{tabular}{llll}
\hline Characteristic & Total $(\mathrm{n})$ & $\%$ & Mean \\
\hline Number of referrals & 1663 & - & 100 \\
Number of admissions & 1135 & 88.9 \\
Number of patients & 1009 & - & 22.8 \\
Average age on admission mean & - & 77.3 \\
Male gender & 877 & 22.7 \\
Female gender & 258 & 6.6 \\
Reported NRPF & 75 & 4.0 \\
Reported self-discharge & 45 & 4.4 \\
Reported deaths & 50 & - \\
Average age of death mean & - & 41.7 \\
No fixed abode/rough-sleeping & 473 & 15.6 \\
Unsuitable accommodation/sofa-surfing & 177 & 22.8 \\
Hostel/ temporary accommodation & 259 & 11.1 \\
Medical care/council house & 126 & 8.8 \\
Unknown/missing data & 100 & 56 \\
\hline
\end{tabular}


Table 3 ICD-10 diagnostic categories with examples

\begin{tabular}{|c|c|c|c|c|}
\hline ICD-10 Code & Example & $\begin{array}{l}\text { Primary } \\
\text { diagnosis } n(\%)\end{array}$ & $\begin{array}{l}\text { Secondary } \\
\text { diagnosis } n(\%)\end{array}$ & $\begin{array}{l}\text { Total } \\
\text { Prevalence }\end{array}$ \\
\hline $\begin{array}{l}\text { I Certain infectious and parasitic } \\
\text { diseases }\end{array}$ & HIV, tuberculosis, hepatitis $B$, hepatitis $C$, sepsis, meningitis & $54(4.8)$ & $16(1.4)$ & $70(6.2)$ \\
\hline I Neoplasms & Cancer: lung, hepatocellular, GIST, renal cell, cervical & $30(2.6)$ & $8(0.7)$ & $38(3.3)$ \\
\hline $\begin{array}{l}\text { III Diseases of the blood and } \\
\text { blood-forming organs } \\
\text { and certain disorders involving } \\
\text { the immune } \\
\text { mechanism }\end{array}$ & $\begin{array}{l}\text { Vaso-occlusive crisis, sickle cell, anaemia, pancytopenia, } \\
\text { myelodysplastic syndrome }\end{array}$ & $12(1.1)$ & $5(0.4)$ & $17(1.5)$ \\
\hline $\begin{array}{l}\text { IV Endocrine, nutritional and } \\
\text { metabolic diseases }\end{array}$ & $\begin{array}{l}\text { Diabetic ketoacidosis, hyperglycaemic hyperosmolar } \\
\text { state, hypokalaemia, SIADH, hyperglycaemia, } \\
\text { hypoglycaemia, Wernicke's encephalopathy, } \\
\text { re-feeding syndrome }\end{array}$ & $39(3.4)$ & $45(4.0)$ & $84(7.4)$ \\
\hline V Mental and behavioural disorders & $\begin{array}{l}\text { Overdose, suicidal ideation, alcohol withdrawal, } \\
\text { intoxication, self-harm, hallucinations, depression, } \\
\text { bipolar, psychosis, schizophrenia }\end{array}$ & $210(18.5)$ & $111(9.8)$ & $321(28.3)$ \\
\hline VI Diseases of the nervous system & $\begin{array}{l}\text { Encephalitis, seizure, status epilepticus, multiple } \\
\text { sclerosis }\end{array}$ & $74(6.5)$ & $5(0.4)$ & $79(6.9)$ \\
\hline VII Diseases of the eye and adnexa & Glaucoma, visual disturbance, blindness, cataracts & $0(0)$ & $0(0)$ & $0(0)$ \\
\hline $\begin{array}{l}\text { VIII Diseases of the ear and } \\
\text { mastoid process }\end{array}$ & $\begin{array}{l}\text { Otitis media, otitis externa, perforated ear drum, } \\
\text { Meniere's disease }\end{array}$ & $0(0)$ & $0(0)$ & $0(0)$ \\
\hline IX Diseases of the circulatory system & $\begin{array}{l}\text { DVT, STEMI, leg ulcers, angina, PE, septic emboli, } \\
\text { heart failure, palpitations, stroke, acute limb } \\
\text { ischaemia, infective endocarditis, AF, oesophageal } \\
\text { varices, } \\
\text { amputation, aneurysm }\end{array}$ & $81(7.1)$ & $20(1.8)$ & $101(8.9)$ \\
\hline$X$ Diseases of the respiratory system & $\begin{array}{l}\text { Pneumonia, T2RF, IECOPD, aspergilioma, pleural } \\
\text { effusion, asthma }\end{array}$ & $83(7.3)$ & $35(3.1)$ & $118(10.4)$ \\
\hline XI Diseases of the digestive system & $\begin{array}{l}\text { Pancreatitis, peptic ulcer, gastritis, decompensated ALD, } \\
\text { diverticulitis, oesophagitis, cirrhosis, cholecystitis, hernia }\end{array}$ & $92(8.1)$ & $14(1.2)$ & $106(9.3)$ \\
\hline $\begin{array}{l}\text { XII Diseases of the skin and } \\
\text { subcutaneous tissue }\end{array}$ & Abscess, cellulitis, dermatitis & $78(6.9)$ & $15(1.3)$ & $93(8.2)$ \\
\hline $\begin{array}{l}\text { XIII Diseases of the musculoskeletal } \\
\text { system and } \\
\text { connective tissue }\end{array}$ & $\begin{array}{l}\text { Osteomyelitis, septic arthritis, limb swelling, dislocation, } \\
\text { back pain }\end{array}$ & $45(4.0)$ & $15(1.3)$ & $60(5.3)$ \\
\hline $\begin{array}{l}\text { XIV Diseases of the genitourinary } \\
\text { system }\end{array}$ & $\begin{array}{l}\text { UTI, CKD, Renal failure, urosepsis, pyelonephritis, renal } \\
\text { stone }\end{array}$ & $37(3.3)$ & $8(0.7)$ & $45(4.0)$ \\
\hline $\begin{array}{l}\text { XV Pregnancy, childbirth and the } \\
\text { puerperium }\end{array}$ & $\begin{array}{l}\text { Caesarean, PPH, miscarriage, multiple gestation, } \\
\text { obstetricdeath, disorders of pregnancy }\end{array}$ & $9(0.8)$ & $0(0)$ & $9(0.8)$ \\
\hline $\begin{array}{l}\mathrm{XVI} \text { Certain conditions originating in } \\
\text { the perinatal period }\end{array}$ & Birth trauma, perinatal infections, newborn disorders & $0(0)$ & $0(0)$ & $0(0)$ \\
\hline $\begin{array}{l}\text { XVII Congenital malformations, } \\
\text { deformations and chromosomal } \\
\text { abnormalities }\end{array}$ & $\begin{array}{l}\text { Any congenital malformations, microcephaly, spina } \\
\text { bifida, transposition of the great vessels, atrial septal } \\
\text { defect. }\end{array}$ & $0(0)$ & $1(0.1)$ & $1(0.1)$ \\
\hline $\begin{array}{l}\text { XVIII Symptoms, signs and abnormal } \\
\text { clinical and laboratory findings, not } \\
\text { elsewhere classified }\end{array}$ & $\begin{array}{l}\text { Unwell, collapse, abdominal pain, acute confusion, } \\
\text { loss of consciousness, syncope, vomiting, diarrhoea }\end{array}$ & $84(7.4)$ & $29(2.6)$ & $113(10.0)$ \\
\hline $\begin{array}{l}\text { XIX Injury, poisoning and certain other } \\
\text { consequences of external causes }\end{array}$ & $\begin{array}{l}\text { Hypothermia, poisoning, head injury, stabbed, } \\
\text { fracture, fall }\end{array}$ & $61(5.4)$ & $80(7.0)$ & $141(12.4)$ \\
\hline $\begin{array}{l}\text { XX External causes of morbidity and } \\
\text { mortality }\end{array}$ & $\begin{array}{l}\text { Road traffic collision, assault, head trauma, } \\
\text { dog bite, deliberate self-harm }\end{array}$ & $89(7.8)$ & $123(10.8)$ & $212(18.6)$ \\
\hline $\begin{array}{l}\text { XXI Factors influencing health status } \\
\text { and contact with health services }\end{array}$ & $\begin{array}{l}\text { Ureteric stent, } C A B G \text {, double cord transplant, } \\
\text { cystoprostectomy, abortion }\end{array}$ & $20(1.8)$ & $57(5.0)$ & $77(6.8)$ \\
\hline XXII Codes for special purposes & New diseases such as Zika virus, antimicrobial resistance & $1(0.1)$ & $0(0)$ & $1(0.1)$ \\
\hline Missing Data & Data unavailable & $36(3.2)$ & $36(3.2)$ & 72 (6.4) \\
\hline
\end{tabular}




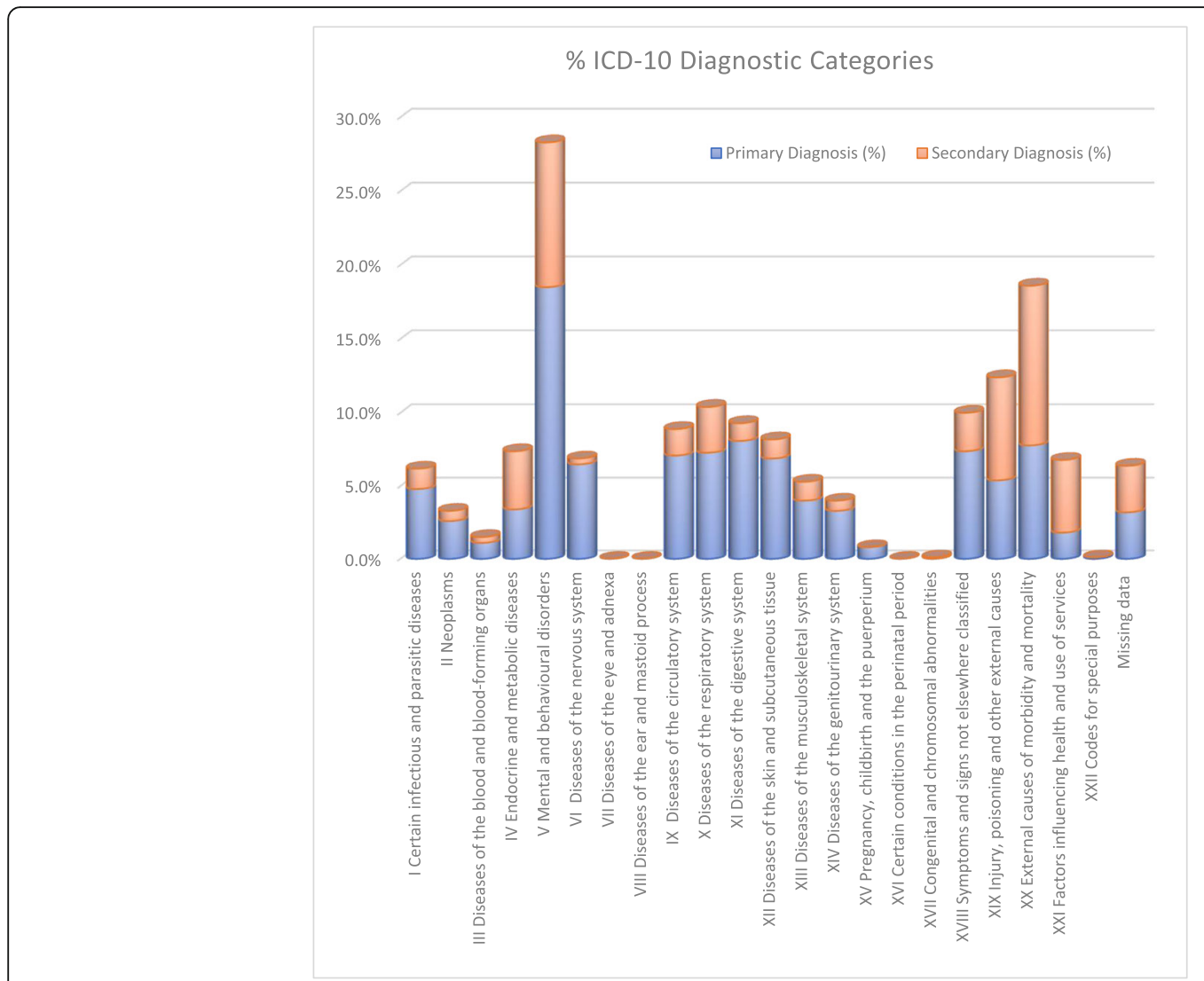

Fig. 1 Representation of total primary and secondary care ICD-10 diagnoses

consequences of external causes made up 12.4\% (fracture (5.6\%), laceration (1.1\%) and brain injury (3.5\%)) and (XVIII) Symptoms, signs and abnormal clinical and laboratory findings not elsewhere classified accounted for $10.0 \%$ of admissions (collapse $(2.0 \%)$, generally unwell $(1.6 \%)$, pain $(2.1 \%)$ and acute confusion $(0.9 \%))$. The primary and secondary categorised diagnoses are represented in Table 4. For full diagnostic characteristics, see Additional file 2. Examples of analysed admissions are included in Fig. 2.

\section{Multi-morbidity of admitted homeless patients}

Almost 95\% ( $n=1077)$ of patients experiencing homelessness who were admitted to hospital had a physical health need either in isolation (40.9\%) or in combination with mental illness $(6.9 \%)$, addictions $(40.0 \%)$, or both $(7.1 \%$ of patients $(n=81)$ had documented tri-morbidity of physical health, mental health and substance use disorders). A small number of admissions were only related to mental illness $(n=4,0.4 \%)$ or addiction $(n=1,0.1 \%)$ and 19 (1.7\%) patients were admitted for mental health needs combined with substance use disorders (Fig. 3). The number of admissions involving substance misuse or mental health issues should be interpreted with caution, as these were not reliably coded within the data reviewed.

\section{Mortality}

Fifty reviewed patients (5\%) died within one-year of discharge from their index admission (Table 5). The average age of death for these patients was 52 years. Of the patients that died, $30 \%(n=15)$, died during their index admission, $16 \%(n=8)$ died within 30-days of discharge and 20\% $(n=10)$ between 30- and 120-days following discharge. More than a quarter $(n=14,28 \%)$ died more than 120-days after discharge. The date of death was not reported for three patients (6\%). Cause of death was only available for those that died during admission as it was not possible to access medical certificates for cause of death (MCCD). Of the 15 patients that died during their index admission, age of death ranged from 29 to 77 years. Over a quarter of these deaths $(n=4,27 \%)$ were the result of trauma, three were cancer-related deaths, three were related to renal failure, two were from sepsis, one from hypothermia, one from diverticular perforation and one patient elected to stop all medications.

\section{Admission and discharge characteristics Trauma related admission}

Of all admissions, $17.1 \%(n=194)$ documented trauma as contributing to the admission (Table 6). The most common trauma was overdose $(6.3 \%, n=72)$, followed 
Table 4 Classification of primary and secondary diagnostic ICD10 in descending order. (N/A not applicable, MD missing data)

\begin{tabular}{|c|c|c|c|c|c|c|c|c|}
\hline \multicolumn{3}{|c|}{ Primary Diagnosis } & \multicolumn{3}{|c|}{ Secondary Diagnosis } & \multicolumn{3}{|c|}{ Total Diagnoses } \\
\hline ICD10 & $n$ & $\%$ & $\mathrm{ICD} 10$ & $n$ & $\%$ & $\mathrm{ICD} 10$ & $n$ & $\%$ \\
\hline V & 210 & $18.5 \%$ & $N / A$ & 512 & $45.1 \%$ & $\mathrm{~N} / \mathrm{A}$ & 512 & $22.6 \%$ \\
\hline$X I$ & 92 & $8.1 \%$ & $X X$ & 123 & $10.8 \%$ & V & 321 & $14.2 \%$ \\
\hline$X X$ & 89 & $7.8 \%$ & V & 111 & $9.8 \%$ & $X X$ & 212 & $9.4 \%$ \\
\hline$X V I I I$ & 84 & $7.4 \%$ & XIX & 80 & $7.0 \%$ & $X I X$ & 141 & $6.2 \%$ \\
\hline$x$ & 83 & $7.3 \%$ & $X X I$ & 57 & $5.0 \%$ & $x$ & 118 & $5.2 \%$ \\
\hline IX & 81 & $7.1 \%$ & IV & 45 & $4.0 \%$ & $X V I I I$ & 113 & $5.0 \%$ \\
\hline$X \|$ & 78 & $6.9 \%$ & $\mathrm{MD}$ & 36 & $3.2 \%$ & $X I$ & 106 & $4.7 \%$ \\
\hline $\mathrm{Vl}$ & 74 & $6.5 \%$ & $x$ & 35 & $3.1 \%$ & IX & 101 & $4.5 \%$ \\
\hline$X I X$ & 61 & $5.4 \%$ & $X V I I I$ & 29 & $2.6 \%$ & $X \|$ & 93 & $4.1 \%$ \\
\hline 1 & 54 & $4.8 \%$ & IX & 20 & $1.8 \%$ & IV & 84 & $3.7 \%$ \\
\hline XIII & 45 & $4.0 \%$ & 1 & 16 & $1.4 \%$ & $\mathrm{Vl}$ & 79 & $3.5 \%$ \\
\hline IV & 39 & $3.4 \%$ & XIII & 15 & $1.3 \%$ & $X X I$ & 77 & $3.4 \%$ \\
\hline XIV & 37 & $3.3 \%$ & $X \|$ & 15 & $1.3 \%$ & $\mathrm{MD}$ & 72 & $3.2 \%$ \\
\hline $\mathrm{MD}$ & 36 & $3.2 \%$ & $X I$ & 14 & $1.2 \%$ & 1 & 70 & $3.1 \%$ \\
\hline$\|$ & 30 & $2.6 \%$ & $\|$ & 8 & $0.7 \%$ & XIII & 60 & $2.7 \%$ \\
\hline$X X I$ & 20 & $1.8 \%$ & XIV & 8 & $0.7 \%$ & XIV & 45 & $2.0 \%$ \\
\hline III & 12 & $1.1 \%$ & $\mathrm{Vl}$ & 5 & $0.4 \%$ & $\|$ & 38 & $1.7 \%$ \\
\hline$X V$ & 9 & $0.8 \%$ & III & 5 & $0.4 \%$ & III & 17 & $0.7 \%$ \\
\hline$X X \|$ & 1 & $0.1 \%$ & $\mathrm{XVII}$ & 1 & $0.1 \%$ & $X V$ & 9 & $0.4 \%$ \\
\hline VII & 0 & $0.0 \%$ & VII & 0 & $0.0 \%$ & $X V I I$ & 1 & $0.0 \%$ \\
\hline VIII & 0 & $0.0 \%$ & VIII & 0 & $0.0 \%$ & XXII & 1 & $0.0 \%$ \\
\hline $\mathrm{XVI}$ & 0 & $0.0 \%$ & $X V$ & 0 & $0.0 \%$ & VII & 0 & $0.0 \%$ \\
\hline$X V I I$ & 0 & $0.0 \%$ & $\mathrm{XVI}$ & 0 & $0.0 \%$ & VIII & 0 & $0.0 \%$ \\
\hline N/A & 0 & $0.0 \%$ & XXII & 0 & $0.0 \%$ & $X \mathrm{VI}$ & 0 & $0.0 \%$ \\
\hline
\end{tabular}

by accidents $(4.6 \%, n=52)$, assault $(3.2 \%, n=36)$, road traffic collision (RTC) $(1.9 \%, n=21)$ and documented suicide attempt $(1.1 \% n=13 \%)$. Some records $(7 \%, n=$ 82) were missing this information.

\section{Drug and alcohol use}

More than a quarter of admissions $(26.4 \%, n=300)$ were related to the immediate consequences of drug or alcohol use (e.g. acute alcohol withdrawal, seizures, or intoxication related falls) (Fig. 4). Alcohol was the main contributor affecting one fifth of admissions $(20 \%, n=$ $193)$ with drugs contributing to $9.8 \%(n=112)$. Five $(0.4 \%)$ of these admissions involved both drugs and alcohol.

\section{Housing outcome on discharge}

Nearly two thirds ( $n=684,60.2 \%)$ of patients' accommodation status remained the same or improved on discharge, with $23.4 \%$ improving $(n=266)$ and a small number of patient's $(n=18,1.6 \%)$ housing status deteriorated). For a large proportion of participants $(n=$ $418,36.8 \%$ ) a discharge destination was not reported in the notes and 15 patients died (1.3\%) during admission.

\section{Secondary care usage}

Across the sample there were $767 \mathrm{~A} \& \mathrm{E}$ attendances in the 120 -days prior to admission averaging 0.68 per patient, decreasing to 0.65 (735 A\&E attendances) during the 120-days after discharge $(p=0.31)$ (Table 7). There were 135 planned admissions (average 0.12 admissions) in the 120-days prior to the index admission, this increased to 283 planned admissions (average 0.25 admissions) in the 120-days following discharge $(p=0.03)$. The 610 unplanned admissions (average 0.54 admissions) in the 120-days prior to admission increased to 654 unplanned admissions (average 0.58 admissions) following discharge $(p=0.12)$. The average length of stay for both planned and unplanned admissions 120-days before admission was 3.49 which increased slightly to 3.9 by 120 -days post-discharge $(p=0.15)$.

Most patients did not use secondary care before or after the index admission, so the median and mode for A\&E attendances and secondary care usage pre and post-index admission was 0 . The maximum A\&E attendances by one patient prior to index admission was 63 , which reduced to 32 following Pathway contact. The most unplanned admissions increased from 48 prior to index admission, to 51 . The most unplanned admissions by a patient were 9 prior to index admission, which increased to 12 following assessment. One patient totaled 187 bed days prior to index admission, following this, the longest total bed days were 101 days. This reflects complex health needs which are likely to need further periods of hospital care.

\section{Discussion}

\section{Statement of principal findings}

This retrospective analysis outlines the characteristics of hospital admissions for people experiencing homelessness in seven specialist hospital-based homelessness teams in the UK. The most commonly recorded diagnoses at admission were categorised as mental and behavioural disorders (alcohol intoxication or withdrawal, selfharm, overdose, suicidal ideation or depression), external causes of morbidity and mortality (assault, road traffic collisions, trauma) and injury, poisoning and other consequences of external causes (poisoning, head injuries and fractures). Most admissions had a physical component and physical illness was commonly associated with substance misuse or mental illness.

Within this study, unplanned secondary care usage was not consistently reduced following support and intervention from a hospital Pathway team. Slight reductions in 


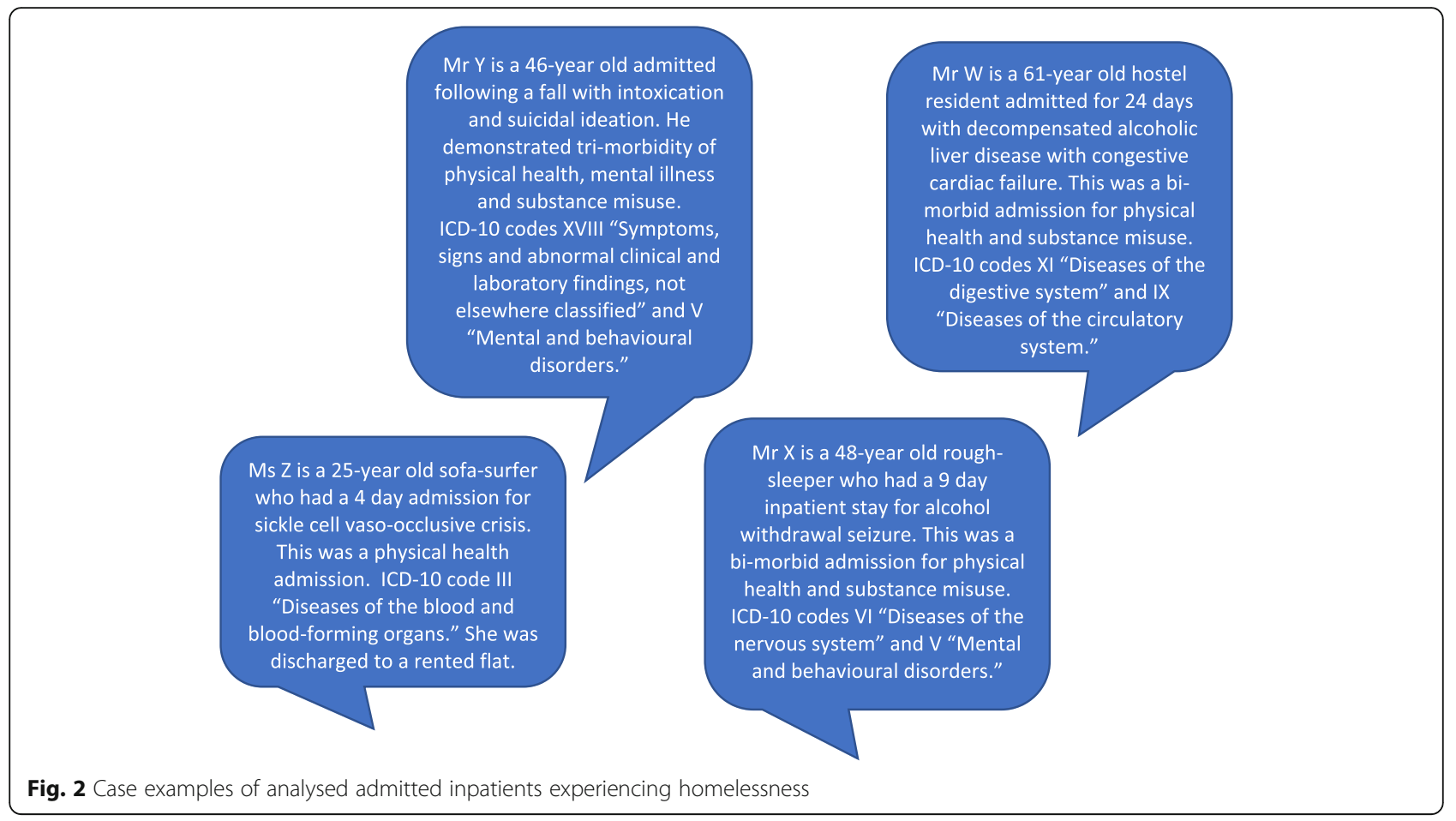

A\&E attendances and a doubling of planned hospital care following contact with a homeless team were observed. Patients experiencing homelessness frequently disengage with healthcare and most deaths in this population are due to treatable medical conditions. Therefore, a significant increase in attending planned admissions is a positive finding as it suggests that patients are receiving necessary investigations, such as follow up endoscopies, procedures, and treatment such as surgery or cancer therapy. Any health attendance is an opportunity to review health, address wider needs, and engage homeless patients into services.

Most patients maintained or improved their housing status on discharge. However, a challenge that was faced within the data was the inconsistent reporting of discharge status. Where data was available, over $60 \%$ of patients $(n=684)$, were discharged to the same type of accommodation or a more appropriate discharge destination. The value in maintaining or improving housing status observed in this research cannot be underestimated, and a great deal of advocacy and negotiation of additional support may be needed to ensure that a patient can return to a hostel that was struggling to support them. The accommodation status of nearly $80 \%$ of Bradford patients improved following admissions, due largely to patients being discharged to Bradford Respite Intermediate Care Support Service (BRICSS), a home from hospital destination for patients experiencing homelessness or with unsuitable accommodation on discharge [40].
More provision of step-down intermediate care (medical respite) could further improve outcomes for homeless patients [41].

\section{Links to existing literature}

Observational studies have found reduced admitted bed days following the introduction of a Pathway team, compared to data for similar patients before the intervention, or matched patients not offered the intervention [10, 33, 34, 42]. A randomised controlled trial of a Pathway team intervention did not show reduced total admitted bed days after the intervention, but did show cost-effectiveness and improved health outcomes [35].

The average age of people experiencing homelessness admitted to hospital in this research was 43 years. This is in-line with previous research from Dublin in which the use of unscheduled emergency department and inpatient care between the housed and homeless population was compared. In Dublin, the average age of inpatients experiencing homelessness was 44 years, whereas that of housed patients was 61 years [43].

Within this study, the average length of stay for admitted patients experiencing homelessness was 14-days. This is consistent with other evidence [3]. For the general population, average length of inpatient stay is 6 days [44]. This difference is explained by the need to resolve multiple health problems alongside wider needs to deliver a safe discharge and community support. This is nearly three times the average of 5 days duration of admission for patients in the 120-days before and after the 


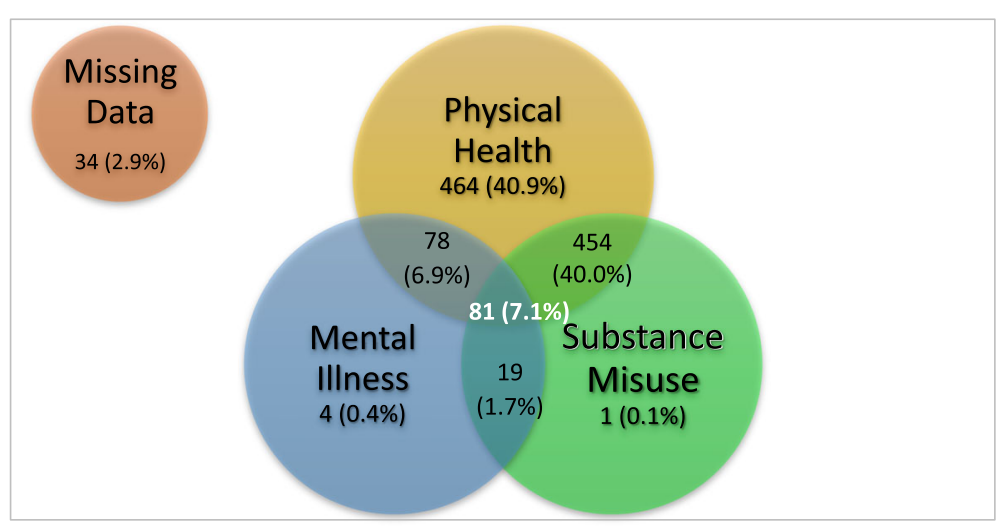

Fig. 3 The tri-morbidities of homelessness

index admission. This suggests that Pathway teams are being appropriately involved at times of complex admissions. The Pathway model is a complex intervention.

A systematic review and meta-analysis of morbidity and mortality in homeless individuals (amongst others) found substantial indices of (I) Infectious diseases and (V) mental and behavioural disorders, a finding that was similar in our research [2]. Previous research exploring the epidemiology of homeless people in high-income countries, including the UK, reports that 9\% of admissions to hospital for this group were prompted by unintentional injuries
[21]. Our figures were slightly higher with $12.4 \%$ admitted for (XIX) Injury, poisoning and certain other consequences of external causes (hypothermia, poisoning, head injury, stabbed, fall) and $18.7 \%$ for XX External causes of morbidity and mortality (RTC, assault, head trauma, dog bite). Fazel concludes that substance misuse and mental health disorders are risk factors for high secondary care usage, an observation consistent with our analysis of biand tri-morbidity [21].

In this research, cause of mortality data was limited to those who died whilst an inpatient within the study

Table 5 Diagnosis and age of patients who died during admission $(n=15)$

\begin{tabular}{|c|c|c|c|c|}
\hline Patient & $\begin{array}{l}\text { Age at } \\
\text { death }\end{array}$ & Diagnosis on admission & Primary ICD-10 & Secondary ICD-10 \\
\hline 1 & 60 & Hypothermia & $\begin{array}{l}\text { XIX Injury, poisoning and certain other consequences } \\
\text { of external causes }\end{array}$ & $\mathrm{N} / \mathrm{A}$ \\
\hline 2 & 66 & Renal failure & XIV Diseases of the genitourinary system & $\mathrm{N} / \mathrm{A}$ \\
\hline 3 & 56 & Distal tibial fracture & $\begin{array}{l}\text { XIX Injury, poisoning and certain other consequences } \\
\text { of external causes }\end{array}$ & $\begin{array}{l}\text { XX External causes of morbidity and } \\
\text { mortality }\end{array}$ \\
\hline 4 & 45 & Renal failure & XIV Diseases of the genitourinary system & $\mathrm{N} / \mathrm{A}$ \\
\hline 5 & 64 & Biliary sepsis & I Certain infectious and parasitic diseases & II Neoplasms \\
\hline 6 & 54 & $\begin{array}{l}\text { Road traffic collision, } \\
\text { cardiac arrest }\end{array}$ & XX External causes of morbidity and mortality & $\begin{array}{l}\text { XIX Injury, poisoning and certain other } \\
\text { consequences of external causes }\end{array}$ \\
\hline 7 & 29 & Renal amyloidosis & XIV Diseases of the genitourinary system & $\mathrm{N} / \mathrm{A}$ \\
\hline 8 & 71 & Fall, cognitive impairment & $\begin{array}{l}\text { XVIII Symptoms, signs and abnormal clinical and } \\
\text { laboratory findings, not elsewhere classified }\end{array}$ & VI Diseases of the nervous system \\
\hline 9 & 39 & Cervical cancer & II Neoplasms & $\mathrm{N} / \mathrm{A}$ \\
\hline 10 & 55 & $\begin{array}{l}\text { Passive suicide - stopped } \\
\text { all medications }\end{array}$ & V Mental and behavioural disorders & $\begin{array}{l}\text { XX External causes of morbidity and } \\
\text { mortality }\end{array}$ \\
\hline 11 & 61 & $\begin{array}{l}\text { Road traffic collision - hit } \\
\text { by lorry }\end{array}$ & XX External causes of morbidity and mortality & $\begin{array}{l}\text { XIX Injury, poisoning and certain other } \\
\text { consequences of external causes }\end{array}$ \\
\hline 12 & 68 & Metastatic lung cancer & II Neoplasms & $\begin{array}{l}\text { XXI Factors influencing health status and } \\
\text { contact with health services }\end{array}$ \\
\hline 13 & 77 & Sepsis & I Certain infectious and parasitic diseases & $\mathrm{N} / \mathrm{A}$ \\
\hline 14 & 60 & Renal cancer & II Neoplasms & XIV Diseases of the genitourinary system \\
\hline 15 & 48 & Diverticular perforation & XI Diseases of the digestive system & N/A \\
\hline
\end{tabular}


Table 6 Characteristics of analysed admissions

\begin{tabular}{lll}
\hline Characteristic & Total patients $(n)$ & Percent \\
\hline Self-discharge & 49 & 4.3 \\
Type of encounter & & \\
Planned & 30 & 2.6 \\
Unplanned & 1105 & 97.4 \\
Surgery or procedure documented & \\
Surgery & 56 & 4.9 \\
Procedure & 22 & 1.9 \\
N/A & 997 & 87.8 \\
Missing data & 60 & 5.3 \\
Admission associated with trauma & \\
Accident RTC & 21 & 1.9 \\
Accident other & 52 & 4.6 \\
Assault & 36 & 3.2 \\
Overdose & 74 & 6.5 \\
Suicide attempt & 13 & 1.1 \\
N/A & 857 & 75.5 \\
Missing data & 82 & 7.2 \\
Housing status on discharge & & 1.3 \\
Improved & 266 & 36.8 \\
Same & 418 & \\
Worse & 18 & \\
Died & 418 \\
Unknown & & \\
\hline
\end{tabular}

period $(n=15)$. The causes of death reported (XX External causes of morbidity and XIX Injury, poisoning and certain other consequences) were similar to those reported in an analysis of 130 homeless deaths in East London [45]. The main morbidities and causes of mortality reported in this study are consistent with the life experiences of people living with poverty, deprivation and social exclusion [2]. Data from the office of national statistics [24] and evidence from Glasgow [46] also demonstrates how premature morbidity and mortality in deprived populations is frequently due to substance use disorders, suicide and violence. In response to the paucity of data around causes, and number of deaths among people experiencing homelessness in the UK, the Bureau of Investigative Journalism have launched an enquiry and are collating data in this area [47].

This retrospective evaluation focused on admissions and secondary health care usage for people identified as experiencing homelessness. While exploring which interventions are effective in supporting this group was not our focus, a recent Lancet systematic review, Luchenski et al. explored "what works" in inclusion health [1]. They reported that providing housing and engaging homeless persons with mental health services (Housing First model) decreased health service use. This correlates with our hypothesis of maintaining housing outcomes for this cohort. Respite care can also reduce secondary care usage, a process supported by Hwang and Burns [48].

\section{Strengths and limitations of the study Identifying participants}

Homelessness is not routinely coded in NHS data. Most studies exploring inpatients experiencing homelessness are therefore dependent on whether the hospital system has coded the patient as having "no fixed abode" (NFA) or no address [49]. Many hospitals will reproduce an old address automatically meaning patients are not correctly identified as potentially being homeless. This analysis drew on the records of specialist homelessness teams, as such, each patient was individually identified as being homeless. This included case notes and discharge summaries which facilitated a more robust understanding of each inpatient episode than would have been obtained by relying on computer coding. Pathway teams are embedded within hospitals meaning that individuals who are or are at risk of becoming homeless are often referred to them. Despite this, it is possible that not all homeless patients presenting at included hospitals were referred to Pathway teams.

\section{Inconsistencies and limitations of included data}

Limited resources and a lack of consistent information in records and discharge summaries posed challenges. The process of collecting and analysing data was labour intensive. One researcher (HF) manually reviewed paper files and collated information held in various locations across the country. Data was often missing or inconsistently recorded, meaning that estimates provided may represent underestimates.

Trends in healthcare access and data recording processes presented issues. Many patients experiencing homelessness may have multiple patient records (for several reasons including different name spellings, and varied date of birth), attendances at other hospitals were not collected. There were a small proportion of duplicate patients who were re-referred and assessed within the six-month period, which was not unexpected given the patterns of healthcare usage of homeless patients described elsewhere [50].

Within 12-months of discharge, 50 patients (5\%) from the cohort died. There is often a delay before deaths in the community are updated on hospital records and this analysis did not cross reference other sources of information. It is possible therefore that other deaths occurred but were not recorded or included in this analysis.

\section{Measuring the impact of hospital-based interventions}

In times of austerity any new health intervention is usually required to offer savings, for example by reducing 


\section{Drug or Alcohol related admission}

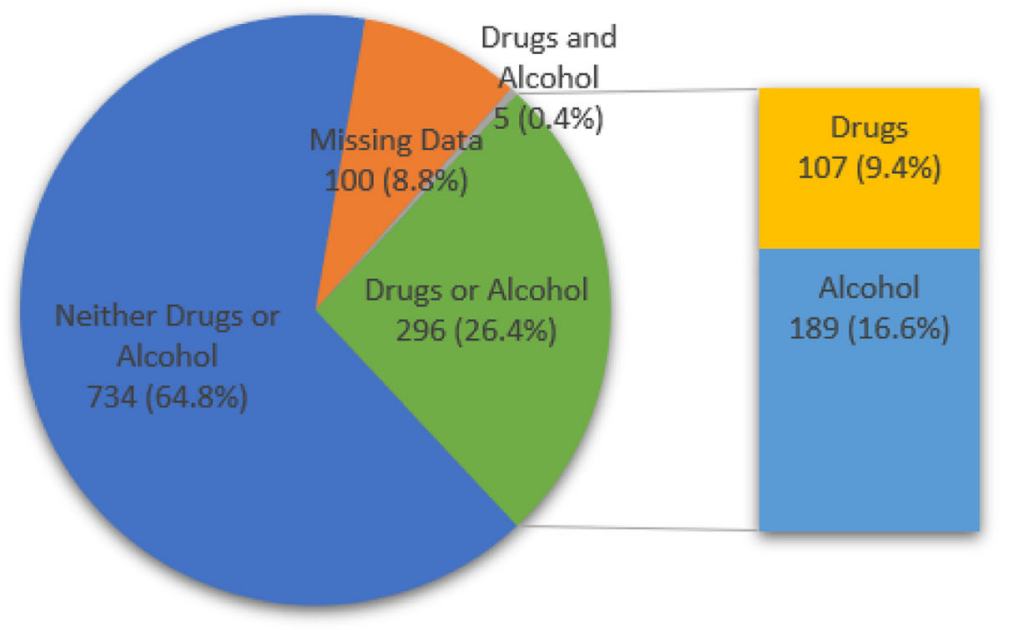

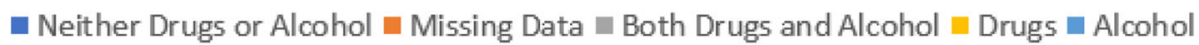

Fig. 4 Drug or alcohol related admission (both, nether and missing data represented)

delayed discharge, or preventing re-admissions. Unplanned hospital admission marks a threshold in deteriorating health, increasing the probability of further acute admissions. Achieving sustained improvements in the health of homeless people needs investment in a range of community health, housing, care and support services [51].

Although total A\&E number of attendances was reduced following the index admission with referral and assessment by a Pathway team, unplanned admissions and bed days increased. As these are complex presentations requiring acute care and a Pathway intervention, it seems likely that the patient is on a downward trajectory which would result in more secondary care usage. This theory is supported by the recent report by Waugh et al. on health and homelessness in Scotland [52]. Waugh described healthcare activity before and after the first homelessness assessment which concludes that this threshold marks a deterioration in health and that homelessness as an event increases secondary care usage [52]. However, we also found a statistically significant increase in planned secondary care usage $(p=0.03)$ following the index admission, suggesting better engagement and more appropriate care.

Our data shows that, when dealing with complex patients who have passed the threshold of requiring acute admission, "before and after data" without a control group is not an appropriate method of measuring the effectiveness of the intervention.

\section{Conclusions}

Meaning of the study: possible explanations and implications for clinicians and policymakers

Across the UK and worldwide, homeless people are being admitted to hospital with acute medical conditions frequently associated with substance use disorders and mental illness [43]. Pathway teams are effective at care coordination and improving wider outcomes including housing, care and support at discharge. The need for these services is underpinned by ethical practice and parity of care to prevent inequity. Rather than seeking in-year savings from the care of deprived and complex patients we should instead apply Marmot's principle of "proportionate universality" [14] and increase resources to meet the needs of some of society's most vulnerable people $[15,19]$. Specialist inclusion health services will continue to be needed but are being challenged by the increasing volume and complexity of patients seen, a lack of appropriate and affordable housing and suitable places of care, a hostile environment towards migrants, overwhelmed social care systems, lack of support services and reducing provision of drug and alcohol services. Long term, government and policy makers must take three actions. Firstly, redress the chronic underfunding of all public services and local authorities alongside mandatory data collection of housing status and recording of deaths of homeless people. Secondly, mandate specialist support (such as Pathway teams) with education and training of all staff to increase the knowledge and skills to address the needs of inclusion health 
Table 7 Secondary care usage 120-days prior to admission and 120-days following discharge

\begin{tabular}{|c|c|c|c|c|}
\hline Characteristic & & Average (SD) & Total & Maximum attendances \\
\hline Index admission & Average LOS (days) & 14 & 14 & \\
\hline \multirow[t]{5}{*}{ Number of secondary care attendances 120-days prior to admission } & A\&E & 0.68 (SD 2.36) & 767 & 63 \\
\hline & Planned admission & $0.12(S D 0.06)$ & 135 & 48 \\
\hline & Unplanned admission & 0.54 (SD 0.03) & 610 & 9 \\
\hline & Total bed days & $3.49(0.33)$ & 3965 & 187 \\
\hline & Average LOS (days) & & 5 & \\
\hline \multirow[t]{5}{*}{ Number of secondary care attendances 120 -days following discharge } & $A \& E$ & 0.65 (SD 2.11) & 735 & 32 \\
\hline & Planned admission & 0.25 (SD 2.79) & 283 & 51 \\
\hline & Unplanned admission & 0.58 (SD 1.31) & 654 & 12 \\
\hline & Total bed days & 3.90 (SD 11.0) & 4430 & 101 \\
\hline & Average LOS (days) & & 5 & \\
\hline
\end{tabular}

groups and those living in poverty. Thirdly, take steps to end homelessness through the provision of a range of social housing and places of care with adequate welfare provision to cover the costs.

\section{Unanswered questions and future research}

Consideration needs to be given to the types of outcome used to assess whether an intervention for people experiencing homelessness with health needs adds value, rather than simply being cost saving. While this retrospective review provides insights into the reasons for admission, morbidity, mortality and secondary health care usage, a more robust design including matched case controls [42] would enable firmer conclusions to be drawn regarding the impact of the Pathway teams' intervention.

Traditionally used outcome measures, such as reductions in health care usage may not accurately reflect positive outcomes for this group. Further research is needed to assess the impact of improved community support on admissions that may be considered an "adversity related admission" such as self-harm, drug misuse, alcohol misuse or violence.

\section{Supplementary information}

Supplementary information accompanies this paper at https://doi.org/10. 1186/s12913-019-4620-1.

Additional file 1. Data extraction template. Blank data extraction document for recording data extracted per patient.

Additional file 2. Full diagnoses of each admitted patient with ICD-10 categories. Full break-down of diagnoses within each ICD-10 category with numbers of patients diagnosed.

\section{Abbreviations}

A\&E: Accident and Emergency; GP: General practitioner; ICD-10: International Classification of Diseases, 10th Revision; IH: Inclusion health; IHG: Inclusion health groups; MCCD: Medical certificate for cause of death; NFA: No fixed abode; NRPF: No recourse to public funds; OT: Occupational therapist; RTC: Road traffic collision; SMR: Standardised mortality rates; UK: United Kingdom

\section{Acknowledgements}

The authors would like to thank the Pathway teams for accommodating and supporting data collection.

\section{Authors' contribution}

$\mathrm{NH}$ and HF conceptualised the study. HF collected the data. HF and $\mathrm{BH}$ analysed the data. HF drafted the initial manuscript. $\mathrm{BH}, \mathrm{NH}$, and ZK critically reviewed several versions of the manuscript, approved the final manuscript and agree to be accountable for all aspects of the work. All authors have read and approved the manuscript.

\section{Funding}

No funding was received for the design of this study, data collection, analysis and interpretation or writing of the manuscript.

\section{Availability of data and materials}

The datasets used and/or analysed during the current study are available from the corresponding author on reasonable request.

\section{Ethics approval and consent to participate}

As a service evaluation this study was exempt from ethical approval requirements [39]. An honorary contract was obtained for HF from each hospital trust for data collection. All data was fully anonymised prior to analysis

\section{Consent for publication}

Not applicable.

\section{Competing interests}

$\mathrm{NH}$ is Medical Director of Pathway Charity.

\section{Author details}

${ }^{1}$ Royal Surrey County Hospital, Egerton Road, Guildford GU2 7XX, UK. ${ }^{2}$ Pathway, 250 Euston Road, London NW1 2PG, UK. ${ }^{3}$ Marie Curie Palliative Care Research Department, Division of Psychiatry, University College London, 6th Floor Maple House, 149 Tottenham Court Road, London W1T 7NF, UK. ${ }^{4} \mathrm{UCL}$ Collaborative centre for inclusion health, Department of Primary Care and Population Health, University College London, London, UK.

Received: 19 June 2019 Accepted: 3 October 2019

Published online: 21 November 2019

\section{References}

1. Luchenski S, et al. What works in inclusion health: overview of effective interventions for marginalised and excluded populations. Lancet. 2017; 391(10117):266-80. https://doi.org/10.1016/S0140-6736(17)31959-1.

2. Aldridge RW, et al. Morbidity and mortality in homeless individuals, prisoners, sex workers, and individuals with substance use disorders in highincome countries: a systematic review and meta-analysis. Lancet. 2018; 391(10117):241-50. https://doi.org/10.1016/S0140-6736(17)31869-X. 
3. Homeless Link (2014) 'The unhealthy state of homelessness: Health audit results'. Available at: http://www.homeless.org.uk/sites/default/files/siteattachments/The unhealthy state of homelessness FINAL.pdf. Accessed September 2018.

4. Blackburn RM, et al. Outcomes of specialist discharge coordination and intermediate care schemes for patients who are homeless: analysis protocol for a population-based historical cohort'. BMJ Open. 2017;7(12):e019282. https://doi.org/10.1136/bmjopen-2017-019282.

5. Elwell-Sutton T, et al. Factors associated with access to care and healthcare utilization in the homeless population of England. J Public Health. 2016: fdw008. https://doi.org/10.1093/pubmed/fdw008.

6. Nambiar D, Stoové M, Dietze P. Frequent emergency department presentations among people who inject drugs: a record linkage study. Int J Drug Policy. 2017. https://doi.org/10.1016/j.drugpo.2017.03.010.

7. Urbanoski $\mathrm{K}$, et al. Frequent use of emergency departments for mental and substance use disorders. Emerg Med J. 2018;35(4):220-5. https://doi.org/10. 1136/emermed-2015-205554.

8. Bramley, E. G. et al. (2015) 'Hard edges: mapping severe and multiple disadvantage'. Lankelly Chase Foundation. England. Available at: https:// lankellychase.org.uk/wp-content/uploads/2015/07/Hard-Edges-MappingSMD-2015.pdf. Accessed September 2018.

9. Davies, J. and Mary, L. (2016) 'Inclusion Health: Education and Training for Health Professionals'. Available at: https://www.gov.uk/government/uploads/ system/uploads/attachment_data/file/490870/NIHB_-_Inclusion_Health_ education_Report.pdf. Accessed September 2018.

10. Dorney-Smith $\mathrm{S}$, et al. Integrating health care for homeless people: Experiences of the KHP Pathway Homeless Team. Br J Healthcare Manage. 2016;22(4):215-24. https://doi.org/10.12968/bjhc.2016.22.4.215.

11. Cornes $M$, et al. Improving hospital discharge arrangements for people who are homeless: a realist synthesis of the intermediate care literature. Health Soc Care Community. 2018. https://doi.org/10.1111/hsc.12474.

12. Crane $M$, et al. Mapping of specialist primary health care services in England for people who are homeless. London; 2018. Available at: https://www.kcl. ac.uk/sspp/policy-institute/scwru/res/hrp/hrp-studies/HEARTH/HEARTHstudy-Mapping-FullReport-2018.pdf. Accessed March 2019.

13. Porter ME. What is value in health care? N Engl J Med. 2010;363(26):247781. https://doi.org/10.1056/NEJMp1011024.

14. Marmot et al. (2008) 'Commission on Social Determinants of Health. Closing the gap in a generation: health equity through action on the social determinants of health. Final Report of the Commission on Social Determinants of Health'. Geneva, World Health Organization. 2008.

15. Crisis (2018). 'More than 170,000 families and individuals across Britain are experiencing the worst forms of homelessness'. $23^{\text {rd }}$ December 2018. Available at: https://www.crisis.org.uk/about-us/media-centre/more-than-1 70-000-families-and-individuals-across-britain-are-experiencing-the-worstforms-of-homelessness/. Accessed March 2019.

16. Fitzpatrick, S. et al. (2018) 'The homelessness monitor: England 2018'. Available at: https://www.crisis.org.uk/media/238700/homelessness_ monitor_england_2018.pdf. Accessed March 2019.

17. Ministry of Housing, communities and L. G. (2017) '2017 Rough Sleeping Statistics'. Available at: https://assets.publishing.service.gov.uk/government/ uploads/system/uploads/attachment_data/file/682001/Rough_Sleeping_ Autumn_2017_Statistical_Release_-_revised.pdf. Accessed September 2018.

18. Ministry of Housing, Communities and Local Government. Rough sleeping statistics autumn 2018. London; 2018. Available at: https://assets.publishing. service.gov.uk/government/uploads/system/uploads/attachment_data/file/ 775089/Rough_Sleeping_Statistics_2018.pdf. Accessed May 2019.

19. Crisis (2018). 'More than 24,000 people facing Christmas sleeping rough or in cars, trains, buses and tents, Crisis warns' 14 $4^{\text {th }}$ December 2018 Available at: https://www.crisis.org.uk/about-us/media-centre/more-than-24-000people-facing-christmas-sleeping-rough-or-in-cars-trains-buses-and-tentscrisis-warns/. Accessed May 2019.

20. Fitzpatrick S, Bramley G, Johnsen S. Pathways into multiple exclusion homelessness in seven UK cities. Urban Stud. 2013;50(1):148-68. https://doi. org/10.1177/0042098012452329.

21. Fazel S, Geddes JR, Kushel M. The health of homeless people in highincome countries: descriptive epidemiology, health consequences, and clinical and policy recommendations. Lancet. 2014;384(9953):1529-40. https://doi.org/10.1016/S0140-6736(14)61132-6.

22. Stringfellow EJ, et al. Primary care provider experience and social support among homeless-experienced persons with tri-morbidity. Addict
Sci Clin Pract. 2015;10(Suppl 1):A64. https://doi.org/10.1186/1940-064010-S1-A64.

23. Hewett N, Halligan A. Homelessness is a healthcare issue. J R Soc Med. 2010;103:306-7. https://doi.org/10.1258/jrsm.2010.10k028.

24. Office for National Statistics (2018) 'Deaths of homeless people in England and Wales: 2013 to 2017'. Available at: https://www.ons.gov.uk/ peoplepopulationandcommunity/birthsdeathsandmarriages/deaths/ bulletins/deathsofhomelesspeopleinenglandandwales/2013to2017. Accessed May 2019.

25. Thomas, B. (2012) 'Homelessness kills: an analysis of the mortality of homeless people in early twenty-first century England'. Crisis; 2012 and The University of Sheffield. 2012 ISBN 978-1-899257-78-2.

26. Rae $B E$, Rees $S$. The perceptions of homeless people regarding their healthcare needs and experiences of receiving health care. J Adv Nurs. 2015;71(9):2096-107. https://doi.org/10.1111/jan.12675.

27. Collier R. Bringing palliative care to the homeless. Can Med Assoc J. 2011; 183(6):E317-8. https://doi.org/10.1503/cmaj.109-3756.

28. Håkanson C, Öhlén J. (2016) 'Illness narratives of people who are homeless'. International journal of qualitative studies on health and well-being. 2016; 11:https://doi.org/10.3402/qhw.v11.32924.

29. Homeless Link (2017) 'Support for single homeless people in England Annual Review 2017'. Available at: https://www.homeless.org.uk/sites/ default/files/site-attachments/Annual Review 2017_0.pd. Accessed September 2018.

30. Lacobucci G. Homeless people's a\&E visits treble in seven years. BMJ. 2019: 1323. https://doi.org/10.1136/bmj.1323.

31. Hewett N, Bax A, Halligan A. Integrated care for homeless people in hospital: an acid test for the NHS? Br J Hosp Med. 2013;74(9):484-5.

32. Pathway, (2018) Available at: http://www.pathway.org.uk/about-us/. Accessed September 2018.

33. Hewett $\mathrm{N}$, et al. A general practitioner and nurse led approach to improving hospital care for homeless people. BMJ. 2012;345:e5999.

34. Wyatt L. Positive outcomes for homeless patients in UCLH pathway Programme. Br J Healthcare Manage. 2017;23(8):p367-71.

35. Hewett $\mathrm{N}$, et al. Randomised controlled trial of GP-led in-hospital management of homeless people ('pathway')'. Clin Med. 2016;16(3):223-9.

36. Hewett N, Hiley A, Gray J. Morbidity trends in the population of a specialized homeless primary care service. Br J Gen Pract. 2011;61(584):200-2.

37. Queen A, Lowrie R, Richardson J, Williamson A. Multimorbidity, disadvantage, and patient engagement within a specialist homeless health service in the UK: an in-depth study of general practice data. $\mathrm{Br} J$ Gen Pract. 2017;1(3):2016-0641.

38. World Health Organisation. (2016) 'International Statistical Classification of Diseases and Related Health Problems, $201610^{\text {th }}$ Revision'. Available at: http://apps.who.int/classifications/icd10/browse/2016/en. Accessed September 2018.

39. Health Research Authority. (2017) Available at: http://www.hra-decisiontools. org.uk/research/docs/DefiningResearchTable_Oct2017-1.pdf. Accessed September 2018.

40. National Housing Federation. (2013). 'Bradford Respite and Intermediate Care Support Services (BRICCS) - Horton Housing Association'. Available at: https://www.housing.org.uk/topics/health-care-and-housing/health-hub/ building-partnerships/briccs/. Accessed September 2018.

41. Dorney-Smith $S$, et al. 'Homeless medical respite service provision in the UK', housing, Care and Support; 2018. https://doi.org/10.1108/HCS08-2018-0021.

42. Khan, Z. et al. (2018) Improving outcomes for homeless inpatients in mental health', housing, care and support, p. HCS-07-2018-0016. doi: https:// doi.org/10.1108/HCS-07-2018-0016.

43. Cheallaigh C, Cullivan S, Sears J, et al. Usage of unscheduled hospital care by homeless individuals in Dublin, Ireland: a cross-sectional study'. BMJ Open. 2017;7:1-7.

44. Organisation for Economic Co-operation and Development. (2018), 'Length of hospital stay (indicator)'. doi: https://doi.org/10.1787/8dda6b7a-en Available at: https://data.oecd.org/healthcare/length-of-hospital-stay.htm. Accessed March 2019.

45. Hassanallay K, Asaria M. Homeless mortality data from East London. London J Prim Care. 2018;10(4):99-102.

46. Walsh D, McCartney G, Collins C, Taulbut M, Batty G. (2016) 'History, politics and vulnerability: explaining excess mortality in Scotland and Glasgow' Glasgow Centre for Population Health, May 2016. 
47. McClenaghan M, Boutaud C. Dying homeless: counting the deaths of homeless people across the UK. Bureau Invest J. 2018; Available at: https:/ www.thebureauinvestigates.com/stories/2018-04-23/dying-homeless. Accessed April 2019.

48. Hwang S, Burns T. Health interventions for people who are homeless. Lancet. 2014;384:1541-7.

49. Office of the Chief Analyst. Healthcare for single homeless people: Department of Health; 2010. Available at: http://webarchive.nationalarchives. gov.uk/20130107105354/http://www.dh.gov.uk/prod_consum_dh/groups/ dh_digitalassets/@dh/@en/@ps/documents/digitalasset/dh_114369.pdf. Accessed September 2018

50. Leicester Homeless Primary Health Care Service. Annual report 2007/8. Leicester: Leicester City NHS Community Health Service; 2008.

51. Hewett N. Standards for commissioners and service providers. V3.1: Faculty for Homeless and Inclusion Health; 2018, 2018.

52. Waugh A, Clarke A, Knowles J, Rowley D. Health and homelessness in Scotland: Scottish Government; 2018, 2018. p. 1-163. Available online https:/www.gov. scot/Resource/0053/00536908.pdf. Accessed September 2018.

\section{Publisher's Note}

Springer Nature remains neutral with regard to jurisdictional claims in published maps and institutional affiliations.

- fast, convenient online submission

- thorough peer review by experienced researchers in your field

- rapid publication on acceptance

- support for research data, including large and complex data types

- gold Open Access which fosters wider collaboration and increased citations

- maximum visibility for your research: over $100 \mathrm{M}$ website views per year

At $\mathrm{BMC}$, research is always in progress. 